\title{
Investors in People
}

Research identified that those organisations that 'invested' in their people resource tended to prosper, and this fact tends to become more and more obvious the more one contemplates it.

Mike Grace e-mail:m.grace.bdj@bda-dentistry.org.uk

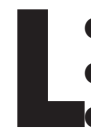
ast month the British Dental Association was recognised as an Investor in People (liP). This is very welcome news, allowing all the staff here to feel pleased that our efforts at running the business of the association effectively have been recognised officially. It should also strike a chord with those few dental organisations that have also been recognised, as we all share in the knowledge of what it takes to achieve this standard.

It is also fitting that the Quality Development Award (QDA) winner from 1997, John Barnet-Lamb, should have his interview published in this issue, as John's practice was also recently recognised for IiP. John used the QDA as a stepping stone along the way to IiP, and his comments in the interview illustrate what he feels achieving the standard has done for his practice.

Investors in People is a national business quality standard that recognises organisations who carry out their normal business practices in a particular way. One aspect of IiP (as the name suggests) is the way the organisation invests in the people in the business, from the managing director (or principal owner) to the cleaner. In essence, the standard concentrates on how effectively the organisation has decided on its direction and objectives, how effectively it communicates these to everyone in the organisation and how well the people are trained and developed so that they are competent to do what they need to do for the objectives to be met. For people keen to find out more about IiP the article in the June 1998 issue of Dental Business by Fiona Stuart-Wilson helps lift the 'mists of confusion' that still surround the standard for some people.

So what difference will the BDA's recognition have for the individual members of the BDA? How will they benefit? One way that has been increasingly apparent over the last few years is the clarity of the BDA's purpose in its mission statement (published in every issue of the $B D J$ ) and objectives. Another is the cost-effectiveness of the training the BDA funds for staff and officers to enable them to carry out their jobs more effectively, from chairing a meeting to acting as spokesperson for the media.

IiP encapsulates the principles of effective business, which is how it was originally developed following extensive research into what successful businesses did to ensure their continuing success. This research identified that those organisations that 'invested' in their people resource tended to prosper, and this fact tends to become more and more obvious the more one contemplates it. After all, people are not only the most expensive outlay for most businesses, but also the most influential. Think back to the last time you communicated with any business (including going into a shop to buy something) and remember how you felt after someone treated you really well; or the reverse.

All of this obviously applies to dental organisations, and I can see some kind of quality standard taking on increasing importance in the future. It seems prefectly feasible that IiP will add to the attractiveness of a practice, whether it be as a potential sale to a corporate body, as an applicant for a contract with the Health Authority or simply to attract new patients. One of the advantages of IiP is that the standard is a national one, and one that is becoming better known generally in the UK. This adds to its potential power in the eyes of others outside dentistry, for whom dental standards are less valid and relevant.

Investors in People is an important recognition, and more and more dental practices are reported achieving it in the dental press. For those still wondering if it is worth it I am sure everyone here at BDA headquarters would encourage people to seriously investigate it, as a successful and effective business benfits everyone involved, especially our customers — the patients. 